\title{
NÑAIT JATÑIL, SOY CABALLO NEGRO
}

\author{
Por \\ David Andrés Zárate Loperena*
}

\begin{abstract}
RESUMEN
La historia de un personaje kumiai que sobresalió como líder de los indígenas de las regiones ocupadas al norte y sur de la actual frontera entre Estados Unidos y México es relatada en este artículo. De varias fuentes historiográficas y de descripciones que hace Ros Mishkwish, se reconstruye el escenario histórico-cultural de este líder kumiai que vivió a fines del siglo XVIII y priacipios de XDX, lapso durante el cual terminaba el dominio de los misioneros dominicos e iniciaba la etapa de México independiente. Jatnil fue un héroe para los kumiai.
\end{abstract}

\begin{abstract}
This article tells the story of a Kumeyaay man that was notable as a leader of the indians living in the occupied region to the north and south of the present border between United States and Mexico.

From various historical sources and descriptions made by Ros Mishkwish the author rebuilds a historical-cultural scenarium of this kumeyaay leader that lived during the last years of the $18^{\text {th }}$ century and first years of the $19^{\text {th }}$ century, time during which the supremacy of the missionaries was ending and the era of independent Mexico was beginning. Jatnil was a hero for the Kumeyaay.
\end{abstract}

Este trabajo se centra en la actividad del jefe indigena Jatñil, quien durante muchos años luchó al lado de los soldados mexicanos por la pacificación de la región denominada como "La Frontera". ${ }^{1}$ Debido a ello, fue el único nativo que adquirió alguna relevancia y quizá por ello el subjefe político Clemente Rojo recogió sus testimonios, únicos en la historia indígena de Baja California. Debemos seńalar que toda la información etnográfica del presente trabajo se debe a Ros Mishkwish y por ello los vocablos aparecen en el kamiai de Nejí (ver figura 1).

- Finado. Investigador que estaba adscrito al Instituto de Investigaciones Históricas de la YABC.

En el caso referido al término frontera significa la región comprendida entre la Misión de San Fernando Velicatá y la Misión de San Diega. El topónimo comenzb a aplicarse poco después de que los misioneros dominicos tomaron posesión del establecimiento de San Fernando de Velicatá en 1773. En síntesis, Frontera es la region que ocuparon los Domínicos despoés de la ocupación de la Alta California por la orden franciscana. 
La siguiente es una breve descripción de cómo era nuestro personaje, según testimonios de sus descendientes. Calistra Tenjil lo describe como un hombre enorme y muy fuerte; Juan Cuñurr, bisnieto, dice que era un hombre enorme y de fiero aspecto y, por último, Juan Mishkwish, nos dice de su abuelo;

Jatñil comandaba a todos los indios de Nejí, Campo, Descanso, San Miguel, Tecate, Juárez, Guadalupe, Ensenada y más lejos, hasta donde se encontraban los Cucapá. Jatñil era un hombre muy sabio, él podía entender todas las lenguas [...] él vivió hasta los noventa años.

Peveril Meigs (1971), quien recogió estos testimonios, señaló que “...sin importar lo que los misioneros hayan pensado de Jatñil, para los indios Mishkwish era un héroe". No ha sido posible precisar la fecha del fallecimiento de Jatñil, pero según testimonio de Juan Mishkwish, le tocó asistir a un kerok (ceremonia fúnebre) organizado por su abuelo a fines de los años ochenta del siglo pasado.

La primera referencia de Jatñil se obtuvo hace ya más de doce años, estudiando los apuntes históricos de 1879 de Manuel Clemente Rojo. En ellos consignó un par de entrevistas a un jefe indígena, al que llamaba indistintamente Jatiñil o Janitin, quien por muchos años auxilio, tanto a militares como a misioneros, a pacificar la frontera de las luchas indígenas. De inmediato se pretendió conocer más sobre el personaje pero, desafortunadamente, pronto descubrimos que las fuentes bibliográficas lo mencionan poco. La siguiente opción fue visitar las comunidades indígenas kamiai de la región pero nunca habían oído hablar de esa persona. Había una explicación para esto, cuando un indígena fallecía su nombre no volvía a mencionarse jamás debido a la creencia de que, si lo hacían, su espíritu al no encontrar reposo, regresaría a importunar a sus familiares. Aún en la actualidad esta condición es de estricta observancia. Los indígenas, inadvertidamente, interrumpen así su tradición oral y por ello difícilmente recuerdan a un ser que haya fallecido cuando menos cien años atrás. No obstante, el geógrafo P. Meigs pudo obtener algunos datos sueltos sobre Jatñil, cuando a fines de la década de los treinta entrevistó a Calistra Tenjil y Juan Mishkwish, ambos kamiai de la banda Mishkwish; este último le comentó que era bisnieto de Jatñil (Meigs, 1971). Posteriormente se pudo establecer que era nieto, según lo dijo Ros, hija de Juan. En esa época sólo se logró poner en claro que Jatñil significaba en español perro negro.

El primer trabajo sobre Jatñil, se basó en las notas etnográficas que la historiadora norteamericana Florence Shipeck obtuvo de la indígena kamiai Delfina Cuero y los testimonios de Jatñil recogidos por Clemente Rojo; entonces se le introdujo como Perro Negro, pero al correr del tiempo 


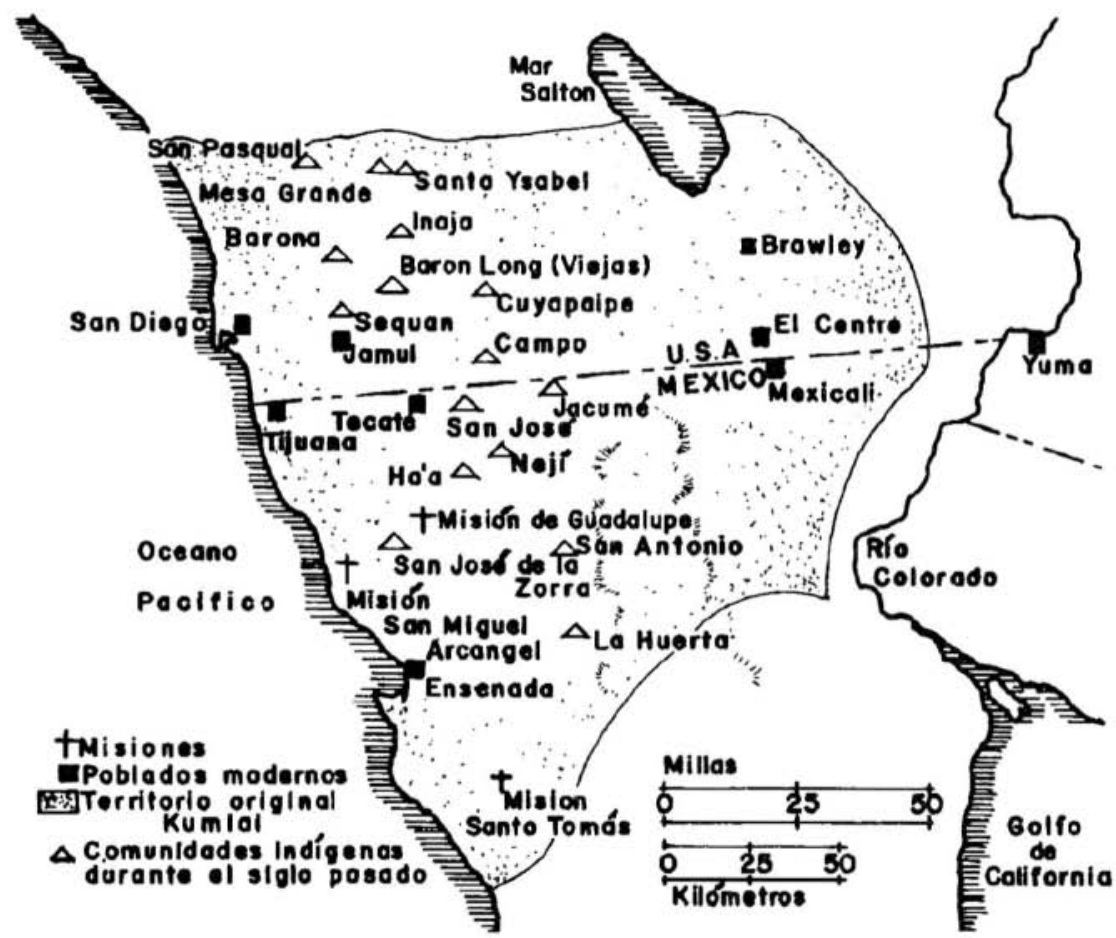

Figura 1. Asentamientos indígenas kumia del sur de California y norte de Baja California. 
e investigando más sobre la etnohistoria de los kamiai, se localizo en 1985 a Rosa Mata Calles o más propiamente Ros Mishkwish Cuijas. Con muchas dificultades, debido a que ella no hablaba propiamente el español, se inicio el aprendizaje sobre esta cultura. La visitábamos cuando menos dos veces por mes en Jakimulj, conocido ahora como Plateros (ver figura 1), en donde lentamente fue adentrándose en su antigua cultura.

Durante esa época se obtuvo una copia en inglés del reporte que hizo el mayor del ejército norteamericano Samuel P. Heintzelman de sus observaciones de los años de 1850-1855, sobre las condiciones de los indigenas del Río Colorado. Este documento, publicado por el gobiemo de Estados Unidos en 1857 dice, entre otras tantas cosas, cómo los kamiai del desierto, al mando de su jefe Charague, o Fuego Ardiente, habian derrotado a los kamiai de la montaña comandados por Huta Neal (tal vez Jatñil) o "Indigo Horse" que traducido al español significa Caballo Negro (Heintzelman, 1857).

Con esta nueva pista, poco después nos encontramos con que la banda Kamiai Jilmiap de Jacumé, aliados de los kamiai $^{2}$ del desierto, siempre habían sido enemigos de los Mishkwish y que ambos habían participado, precisamente en Jacumé, en la derrota de las fuerzas del teniente Macedonio González ${ }^{3}$ en el mes de febrero de 1837, quien por cierto, gracias al arribo de Jatñil y sus hombres, pudo sal var su vida y la de 25 soldados más. Después de lo anterior no hubo duda de que Perro Negro y Caballo Negro era la misma persona. Posteriormente encontramos en el periódico San Diego Union una nota fechada el 3 de marzo de 1870 donde decía que el jefe Huta Neel continuaba auxiliando a las autoridades de La Frontera en la captura de malechores. Seguros que el Huta Neal de Heintzelman y el Huta Neel del periódico de San Diego eran la misma persona, se realiza una nueva visita a Ros Mishkwish para ver qué explicación podfa obtener al respecto. Nos informó que el vocablo jat antiguamente había significado coyote, como el caso de jatipá, el hombre que de acuerdo con las viejas leyendas se convirtió en coyote. También mencionó a un jefe indigena que había vivido en Ilkichup, La Zorra, cercano al actual San José de la Zorra,

2 Kamiai es el nombre que se les da a los indigenas hablantes de una lengua de la familia lingúfrtica yumana que habitaban lo que ahora son los municipios de Tecate. Tijuana, porciones del norte del municipio de Ensenada y del Condado de San Diego, California. Se les denomina también kumiai, diegueffo y tipai.

El teniente Macedonio Gonzalez estaba al frente de los 25 hombres que formaban Ia guarnición de $S$ an Vicente cuando se sucitó en 1836 un alzamiento indígena en Jacumé, a 80 $\mathrm{km}$ al noroeste del Valle de Guadalupe. Los rebeldes a quienes se unieron también algunos yumas atacaron también San Diego, lugar al que acudió en auxilio el mencionado teniente. logrando incorporar en el camino a Jattil. 
cuyo nombre había sido Jatnur, es decir, Coyote Pinto. Cuando se le preguntó si cabía la posibilidad de que Jatñil significara Coyote Negro, su respuesta fue mao (¡no!). Después se le preguntó si el nombre podra significar perro negro, señaló a su perro de color negro y nuevamente su respuesta fue, mao. Con dificultad seguimos la explicación de Ros quien terminó diciendo: Jatñil, kuatai, es decir, grande, no como perro. Al día siguiente se aclaró que antiguamente los indígenas le llamaban nñajat al caballo, vocablo que posteriormente sustituyeron por el de "cabay", asf pues, no quedó ninguna duda, nñajatñil antiguamente y Jatñil en la actualidad, significan lo mismo, Caballo Negro. También vale comentar que el nombre de estos indígenas debería de pronunciarse $k$ 'miai pero, ya que el castellano no utiliza el apóstrofe para facilitar su pronunciación se optó por la castellanización del vocablo y lo dejamos simplemente en kamiai. Quizá sea la misma razón para que en Estados Unidos se les llame kumiai, es decir, optaron por la americanización del fonema, aún cuando cabe advertir que en los trabajos del antropólogo Kroeber (1996) sobre los indígenas de California, y en los del etnólogo Drucker, se consigna que los nativos de la sierra se identifican a sf mismos como kamiai.

\section{LOS KAMIAI}

La cultura de los kamiai, por ciertas características que la distinguen del resto de los grupos étnicos de Baja California, presenta varias facetas para su investigación etnohistórica. Sobresale, primeramente, la gran extensión territorial que ocuparon. Su límite septentrional, un poco al norte del río San Dieguito, se localizaba a unos cien kilómetros al norte de la actual línea fronteriza entre México y Estados Unidos y, hacia el sur, bajando por la costa del océano Pacífico, se adentraba en territorio mexicano unos 150 kilómetros, hasta la ex misión de San Vicente Ferrer, quedando así establecido su límite occidental. Hacía el este, por el norte, llegaba a la margen oeste del río Colorado y por el sur partiendo del Pacífico, trazamos una línea imaginaria que pasaría un poco por debajo de la ex misión de Santa Catarina, para ir a caer a la Laguna Salada o Macuata, de mamtcuaty (cerro grande), haciendo referencia naturalmente a $\mathrm{La}$ Rumorosa, calculamos toda esta área en un poco más de diez mil kilómetros cuadrados. Es decir, comparando con todo el espacio ocupado por el resto de las etnias norpeninsulares, los kamiai ocupaban un territorio seis veces mayor.

Resulta de interés que los kamiai, por su posición geográfica, estaban constituidos en la frontera lingüística entre la familia yumana, a la cual pertenecían, y los hablantes shoshones del tronco uto azteca, particularmente 
con los cahuilla, cupeños y luiseños. Otro de sus rasgos es el hecho de que habitaron los tres ecosistemas norpeninsulares, es decir, la costa, montaña y desierto y esto, aunado a lo anterior, les posibilitó la población más numerosa, probablemente entre ocho mil y diez mil individuos (Shipeck, 1982). En consecuencia, tuvieron un mayor número de bandas y quizá por ello, de variantes dialectales (Zárate, 1987b).

En la época histórica aparecen otras variables. Fue en territorio kamiai donde se establecieron el mayor número de misiones: San Diego de Alcalá y su visita Santa Isabel, ${ }^{4}$ San Vicente Ferrer, San Miguel Arcángel, Santo Tomás de Aquino, Santa Catarina, El Descanso y Nuestra Señora de Guadalupe. Debemos incluir aquí el poblado Misión de San Pedro y San Pablo Bicuñer fundado en 1781, què aunque en tierras de los kwitsan tuvo influencia en las bandas kamiai del desierto (Zárate, 1987b). Otro dato importante es que en sus dominios operaron simultáneamente dos órdenes religiosas, franciscanos en la Alta California y dominicos en Baja California; por último, fueron los kamiai quienes más muertes violentas causaron a los religiosos: dos misioneros en Santo Tomás, uno en San Diego y cuatro más en la región del Colorado, cuando las bandas kamiai del desierto apoyaron a los kwitsan, durante el ataque a los poblados de la Concepcion y Bicuñer. Los kamiai a diferencia del resto de los indígenas, lucharon por más años en contra de la ocupación novohispana y mexicana, desde la fundación de San Diego en 1769, hasta la destrucción de Santa Catalina en 1840. Además, como consecuencia de la guerra entre Estados Unidos y México, su territorio quedó entre ambas naciones, particularidad que comparten con los cucapá.

\section{MATUM NÑAKUR TAIÑWA. HACE MUCHOS AÑOS QUE ESTAMOS AQUí}

Las primeras noticias sobre los kamiai de la costa nos llegan de la expedición peninsular de Rivera y Moncada hacia el puerto de San Diego en 1769. Su diarista, el franciscano Crespí consignó en los primeros días de mayo, a su paso por Ensenada, interesantes datos sobre su vestimenta y habilidad para navegar en sus pequeñas balsas. También notó cierta belicosidad de los nativos, al tratar de entablar relaciones con ellos. Tres semanas después, al paso de la segunda expedición, el Padre Serra tuvo una impresión completamente distinta, al anotar en su diario que los

\footnotetext{
4 Visita es una estancia temporal construida de adobe y ubicada entre un centro religioso misional y otro para servir de parador y de punto de referencia para exploradores y viajes de misión en misión.
} 
imdígenas de la bahía le habían robado el corazón (Gómez, 1969). Aparentcmente, Serra fue el único novohispano gratamente impresionado por los nativos porque el gobernador Pedro Fages y el dominico Luis Sales se cxpresaron en otros términos, señalándolos como agitados, broncos, orgullosos y aguerridos (Fages, 1787) o bién, de recio genio, altivos de sobremanera, valientes y guerreros (Sales, 1960), comentarios que se deben a que los nativos costeños establecidos entre Ensenada y la recién fundada misión de San Miguel, convocaron en Ensenada, en 1787, a cincuenta rancherías para atacar a los novohispanos. Aun cuando les fue posible a los soldados sofocar la rebelion, tras aprehender a varios jefes y cnviarlos al presidio de San Diego, esto les costó muchos problemas y peligros; todavía años después, los indígenas hostigaban constantemente a los soldados, quienes temían más a los ataques con hondas. De acuerdo con los documentos de la época, queda la impresión que las bandas de la bahía ejercían el control ideológico sobre las otras rancherías Kamiai. Al iniciar el siglo XIX, las misiones, salvo el caso de Santa Catarina, por encontrarse propiamente en la costa, no ejercían influencia alguna sobre los indígenas de la sierra, razón muy probable para que el liderazgo fuera tomado por los indígenas serranos, particularmente por los Mishkwish de Nejí.

\section{SA.U. NACIMIENTO}

Matuam nñakur, Jatñil sin'tu'wa. Hace tiempo, aquí vivió Jatñil, fue el comentario de su bisnieta, Ros Mishkwish. Nuestro personaje debi6 nacer hacia finales del siglo dieciocho en Chip Chip, conocido hoy como La Ciénega (comunicación personal con Ros Mishkwish, 1983-1986).

Los kamiai no tomaban la educación de sus hijos a la ligera, por el contrario, eran bastante estrictos en cuanto a la conducta infantil. Cuestiones como el obtener un "buen corazón" eran tratadas por los padres indistintamente del sexo de sus hijos, aun cuando existía cierta enseñanza de padre a hijo y, también de madre a hija (Zárate, 1986). Había muchas reglas para el comportamiento infantil, por ejemplo: Si una persona adulta estaba de visita, les quedaba prohibido correr frente a su casa y para poder entrar a ella, tenían que solicitar autorización. El respeto a los ancianos o el no burlarse de personas con defectos físicos era de absoluta observancia. También los padres ponían mucho énfasis para que los jumí o pchai, niños o niñas, no fuesen a molestar a sus vecinos (Shipeck, 1970). Los adultos aprovechaban cualquier situación para dar un ejemplo correcto a sus hijos y los exhortaban a ofrecer comida a los visitantes, o bien, les señalaban que si querían crecer y ser buenos cazadores deberían de ser aseados. Para 
los castigos, que por lo común quedaban en reprimendas, los padres ocasionalmente usaban varitas de sauce con las que golpeaban a sus hijos en las piernas.

Jatũil quizá participó en una gran variedad de juegos y pasatiempos, algunos consistían en lo que podríamos llamar "guerritas" en donde los niños se arrojaban jamcha (calabazas silvestres) a la cabeza. De acuerdo con Delfina Cuero, de vez en cuando éstas terminaban en pequeñas trifulcas para quedar olvidadas al siguiente día (Shipeck, 1970). El resbalarse por laderas (tjipor) estaba entre sus juegos preferidos, igualmente las carreras por el campo (yuñap) y nadar en los represos (jau'pa) (Zárate, 1986). Otro juego era el otorr (patear la pelota a una meta) y sin duda alguna palitos o cañuela. Ya un poco más grande Jatñil tal vez aprendió a elaborar atim (arco) y a'pa (flecha), wi kuá (enderezador de flechas) japerwí (palo de cacería), ta-lis (honda) y tlajuay (mazo de guerra) con los cuales participaría en competencias de destreza (Mishkwish, comunicación personal, 1983-1986).

\section{MA.ATU UMULJIT, BAUTIZO}

De acuerdo con la tradición kamiai, los jamai o jachain recib́an su nombre entre los siete y ocho años de edad, tras haber asimilado el aprendizaje inicial sobre los usos y costumbres familiares, lo que ya había definido su carácter y temperamento. La ceremonia del bautizo, conocida como matium, estaba asignada al orador, kulpai tium, personaje encargado de comunicarle a la comunidad los eventos o ceremonias. Para este caso, se aseguraba que la instrucción de los niños, iniciada dos semanas antes del evento, fuera la adecuada (Mishkwish, comunicación personal, 19831986). La ceremonia comenzaba al encenderse una fogata, señal para que iniciaran las danzas y juegos. En un momento determinado se invitaba al jefe y al hechicero para que se hicieran presentes y señalaran a cada niño el nombre que les habían escogido. Después algunos ancianos les advertían que ya eran seres humanos, por lo que deberían llevar una vida recta y honrada. Concluida la amonestación a cada quien se le preguntaba por su nombre chma mishi, a lo que nuestro personaje debió responder: nñait Jatñil, soy Caballo Negro (Mishkwish, comunicación personal, 19831986). Después de su bautizo, los niños —entre ellos Jatñil— se adentraban en las actividades de recolección y preparación de alimentos, ya que todos los niños pasaban la mayor parte del tiempo al lado de las mujeres. Posteriormente, entre los nueve y diez años de edad, iniciaban su adiestramiento en la cacería y la guerra, lo que los preparaba para los ritos iniciativos de la adolescencia. 


\section{WIK NISPITSCH, INICIACIÓN}

Los kamiai pensaban que el ser humano pasaba por dos etapas peculiares de receptividad, por lo que las experiencias en la pubertad y adolescencia dejarían efectos permanentes en el cuerpo y el espíritu (Waterman, 1910). Si el matium le daba al indígena su identidad como ser humano, el wik nispitsh lo prepararía como guerrero destinado a grandes eventos heroicos. El ritual comenzaba semanas antes de la ceremonia, cuando el cusiay cuatay se retiraba a localizar el kursha (Datura inoxia) (Cortés, 1988). De regreso a la aldea, el gran hechicero ponía a secar la raf́ de toloache, para luego colocarla con el resto de los objetos ceremoniales (Mishkwish, comunicación personal, 1983-1986). Cuando llegaba el día señalado para la iniciación, ya se había seleccionado una casa para el ceremonial en donde el cusiay cuatai depositaba los parafernales de la siguiente manera: primeramente instalaba el mortero ( $\mathrm{jmu}$ ) decorado con líneas rojas y negras (Waterman, 1910) y a continuación las tablas ceremoniales (kotat) y las plumas de tecolote. Luego trazaba un círculo en el suelo (mai), que representaba el Universo y dentro de éste dibujaba el Sol, las Lunas nueva y llena, algunas constelaciones como Orión y las Pléyades; también se cuidaba de incluir animales como el cuervo, el lobo o el león y el coyote; en la parte media dibujaba el espinazo del diablo (maikurr), la Vía Láctea, flanqueada horizontalmente por dos serpientes. Por fuera del círculo, el Este era representado con dos montañas: Wikami, lugar de origen de los kamiai, y la segunda, Mat cusiai o cerro encantado, localizado particularmente de acuerdo al punto geográfico en donde se celebraba la ceremonia. Al oeste del círculo dos islas, primeramente la de Santa Catalina, de donde provenía el culto al wik ñispitsh y la segunda, representando al Mat cusiay de las islas Coronado o Todos Santos, nuevamente de acuerdo al sitio del ceremonial (Waterman, 1910). El jefe (kulpai) procedía a colocar el jmu (mortero) que contenía la raíz de kursha al oeste de la Vía Lactea y dos jmukey (manos de molienda) al norte y sur del mortero, quedando frente a las cabezas de las serpientes.

De esta manera, todo quedaba listo para la ceremonia en la que sólo participarían los iniciados en el wik nispitsh y de quienes se afirmaba que los poderes mágicos que habían adquirido les permitían caminar sobre el fuego o matar un águila con sólo hechizarla (Waterman, 1910).

Cuando los jóvenes eran introducidos a la uja wachiyeu (casa en donde se baila) algún anciano comenzaba a machacar la raíz en el mortero, mientras que otro entonaba cantos alusivos. El recipiente pasaba luego de mano en mano por todos los ancianos, quienes simbolicamente molían la datura, mejor conocida como toloache. Al finalizar, se vertía un poco de 
agua tibia en el mortero y cada adolescente era invitado a beber del utensilio hasta que algún hechicero le indicaba que era suficiente (Waterman, 1910). Antes de que el narcótico causara su efecto se les instruía en sus futuras obligaciones, bajo las más severas amenazas, si su comportamiento era indebido. Se les explicaba el orden cósmico y de cómo su conducta ayudaria a conservarlo. Mientras tanto, en el centro del sitio destinado para las danzas, las bandas participantes tenían lista una gran fogata. Cuando los iniciados salían se les designaba un "padrino", que sería su instructor en los dos meses que duraria el ceremonial. Pasada la acción del kursha al adolescente se le explicaban sus visiones o sueños. Proseguian con ayunos, competencias y pruebas para fortalecer el cuerpo y el espíritu. El último dí, después de dos meses de agotadora competencia, casi al amanecer, cuando las llamas ya habian desaparecido, los iniciados se colocaban en fila frente a las brasas y caminaban sobre ellas sin gestos ni llanto. Al final de la prueba recibian su kotat o palo ceremonial adornado con plumas de tecolote, lo que significaba que podrían participar como hombres en los futuros eventos. De esa manera Jatñil recibió la distinción de ser considerado joa kamiai (guerrero). El hechizo del oeste le había dado sper e shmap uwiu (fortaleza y sabiduría) (Zárate, 1987a).

El culto al toloache y su introducción a la ceremonia de los adolescentes es históricamente reciente. Se origino en las islas de Santa Catalina y San Clemente y llego a las costas de California al tiempo que los franciscanos fundaban las primeras misiones (Waterman, 1910). Dada la escasa información, no ha sido posible determinar si el culto y el movimiento mesiánico que se originó posteriormente (Du Bois, 1905) se dio con la intención de evitar la introducción de una cultura extraña $o$, más bien, sólo fue una coincidencia histórica. Lo cierto es que los seguidores del culto reclutaron adeptos en las misiones de San Gabriel Arcángel, San Juan Capistrano, San Luis Rey y San Diego de Alcalá, para fortalecer el movimiento revitalizador de sus costumbres y evitar la desintegración cultural (Van Camp, 1979). El wik nispitsh (iniciación) fue adquiriendo popularidad en la medida que el cristianismo iba desarticulando la fuerza de las creencias más antiguas.

Nña apa Jatñil niche: Me llamo Jatñil y soy el capitán de esta tribu. desde el año en que se fue para el Sur el teniente Ruiz (1822); mi padre fue capitán antes de mí y, primero que mi padre, lo fue mi abuelo, de manera que el mando de nuestra tribu estuvo siempre a cargo de mi familia... (Rojo, 1987).

Caballo Negro fue capacitado para el liderazgo. Tuvo que aprender los distintos dialectos kamiai (Meigs, 1971) y algunas lenguas vecinas, como 
parte necesaria para la concertación de alianzas en las guerras intertribales y naturalmente, todo lo concerniente a las distintas ceremonias, puesto que como jefe, sería el guía de ellas (Shipek, 1982). Entre los kamiai era un requisito ser diestro en la guerra y hábil diplomático; de tal manera que cuando Jatñil heredó el cargo de jefe, tuvo que esperar el término de la ceremonia funeraria dedicada a su padre, para refrendarlo ante el consejo de ancianos de las bandas pertenecientes al shimul linaje Mishkwish, quienes en última instancia estaban facultados para desaprobar su designación en caso de no considerarlo apto para el puesto (Meigs, 1971). Después que Jatñil fue confirmado en su cargo de kulpai, debió de esperar un año, porque a los tipai (seres humanos), no se les permitía participar en ninguna ceremonia durante el luto.

Cuando asumió el liderazgo, existían dos tipos de guerras, las indígenas propiamente y la de éstos en contra de las fuerzas novohispanas. Jatñil heredó la guerra de sus abuelos en el primer caso, no obstante, trabó alianza con los soldados y misioneros. He aquí su explicación: "Mi padre me decía que esta tierra sería de las gentes de razón y que no fuese yo contra ella, así como no fueron él, ni mi abuelo; todos fuimos siempre amigos de los blancos..." (Rojo, 1987). Los comandantes de la frontera como Macedonio González, Antonio Garraleta y Estanislao Armenta, ante la insuficiencia de las fuerzas militares siempre solicitaron la alianza de Caballo Negro (Forbes, 1975), lo mismo que Fray Félix Caballero (Rojo, 1987). En cuanto a su apoyo a los dominicos, Jatñil lo dice de la siguiente manera:

... yo, le ayudé al padre Caballero, a levantar la misión del Descanso, desde sus cimientos hasta el fin... [y] vine a ayudarle al padre Félix a levantar la misión de Guadalupe [...] también le ayudaba a sembrar todos los años y a levantar sus cosechas ... (Rojo, 1987).

Jatñil mantuvo su compromiso de lealtad desde 1822 hasta 1839 (Forbes, 1975).

\section{JOA KAPKAU ÑUP, INICIAR LA GUERRA}

Poco sabemos de los preparativos kamiai para la guerra o de aspectos tácticos o estratégicos, sin embargo las fuentes bibliográficas y la tradición oral nos dan alguna idea. De acuerdo con la informante Ros Mishkwish, la noche anterior a la kapkau uiñup (lucha contra el enemigo), los kamiai acostumbraban a danzar durante la noche (jatup imâ). Poco antes de entrar en batalla se pintaban la cara (kuasim tiñur) con polvo recogido del interior de algún encino en descomposición. Para las batallas formales, es decir, ataques frontales bien organizados, se formaban tres grupos, pongamos 
por caso, de cien guerreros cada uno. El primero estaba formado por arqueros, quienes mientras avanzaban comenzaban a disparar sus flechas a cierta distancia, ocasionalmente envenenadas con chamizo caliente, hacia el enemigo. Una sección del mismo grupo atacaba con talís (la honda), quizás el arma más temida por los soldados; de hecho, todos los guerreros iban provistos de ellas. Detrás de éstos venía un segundo grupo provistos de $i$-im joay, especie de bastones que terminaban en punta o bien, lanza corta; otros, con macanas planas (pperwí o jampu) otros más con miltcis (palos curvos o sables de madera dentada) que arrojaban a corta distancia o bien, golpeaban con ellos al cuerpo. Por último, venían los garroteros, provistos del tlajuay o macana de mezquite, dedicados a rematar a los caídos. En el caso de que los kamiai fueran atacados en su propia ranchería, entonces las mujeres y niños se encargaban de esta acción. Si la guerra terminaba con un triunfo (niu mart uiya) nuevamente se celebraría con jatup imá. Esta información debe verse con cierta reserva debido a que la informante era mujer y las "cuestiones de la guerra" pertenecían al sexo masculino, salvo lo señalado anteriormente. También porque las guerras indígenas habían terminado alrededor de 120 años atrás; aunque, en el caso de Ros, su padre Juan luchó en contra de los mexicanos en diferentes ocasiones a fines del siglo pasado y a principios de éste, tal vez durante los movimientos floresmagonistas y quizá ello le permitio tener fresco el conocimiento.

\section{JOA T'IPEI JIKU, LA GUERRA DE LOS INDIOS MEXICANOS}

Durante la primera década de 1800 , la resistencia indígena se estableció en las montañas de Santa Catalina. El comandante de La Frontera, Alferez Ruiz Carrillo, frecuentemente realizo expediciones punitivas. En 1803, con motivo de los asesinatos de los dominicos de la misión de Santo Tomás, Miguel López, en el mes de enero, y el de Eduardo Surroca en mayo (Zárate, 1991a), los catecúmenos huyeron a las montañas y después se refugiaron en el desierto. Ruiz, pensando que se trataba de una sublevación, ocupó lo que restaba del año en salir con su tropa en busca de los indígenas de la misión de Santo Tomás, corriendo con poca fortuna. En el mes de abril de 1804, el cabo Estanislao Salgado envió a San Vicente a cinco prófugos capturados, bajo la custodia de los soldados José Cruz Higuera y Juan Domingo Camacho. Cuando transitaban por el paraje de Agua Blanca los nativos lograron desatarse las manos y acometieron a los soldados con piedras, matándolos en el acto. Ruiz partió el 16 de septiembre con rumbo a la misión de Santa Catalina, en donde ataco a la ranchería. (Arrillaga, 1804). Nuevamente, en el mes de octubre, Ruiz acudio a Santa 
Catalina debido a que algunos indígenas habían herido de flecha a una mujer de la misión. Tras localizarlos Ruiz los acometió durante la madrugada. Fueron sorprendidos y poco pudieron hacer para evitar que la tropa matara a su líder. Dos días después el cabo Salgado, con diez hombres más, salió en su persecución, logrando matar a uno y herir a tres más.

Sobre los siguientes años aún no se dispone de información pero sí sabemos que durante el periodo de lucha por la independencia de México, los sueldos dejaron de llegar a la península, trayendo como consecuencia la penuria de La Frontera. Los soldados tampoco recibieron las vituallas y armas necesarias para continuar con la pacificación indígena. Al sucederse los primeros años de la lucha independentista, las tribus del desierto hicieron más frecuentes sus ataques a los ranchos de la costa.

La década de los veinte sería un preludio de los próximos treinta años. En enero de 1824 la tropa al mando de José María Estudillo perdió, a manos de los indígenas, 75 caballos y 35 mulas. Ese mismo año, las relaciones entre indígenas y mexicanos comenzaron a deteriorarse debido a que los kamiai de San Diego, San Miguel y San Vicente, aliados con algunos gentiles de esas mismas misiones, empezaron a matar ganado y robarse caballos. El 21 de junio del mismo año hubo un enfrentamiento en San Miguel en donde murieron 15 kamiai cristianos incluyendo el jefe Fidelis. Como respuesta, los kamiai contraatacaron en el rancho Nacional, aledaño a San Diego, incendiándolo y matando a un sirviente, continuaron con el Rancho del Valle, dando muerte a un pastor y a un niño (Bean y Mason, 1962). Días después, en un golpe de verdadera audacia, sustrajeron 140 animales de la caballada del presidio de San Diego y posteriormente hicieron lo mismo en la misión de San Miguel, a cargo del Padre Caballero (Forbes, 1975). Los caballos quedaron como propiedad de los Kwitsán de Yuma, después de las ventas de los kamiai. Los dominicos, alarmados del cauce que iban tomando los ataques indígenas y temiendo una insurrección general proveniente del Colorado, fortificaron aún más la misión de Santa Catalina.

El 5 de abril de 1825 se desató la represión de los soldados, cuando las fuerzas del Alférez Ibarra dieron muerte a 28 kamiai en San Felipe y dos días después a 43 más (Forbes, 1975). En la primavera de 1834 se alzaron los indígenas koal de la Misión de Santa Catalina y amenazaron con atacar San Vicente, sin embargo, el Alférez González los atacó a punta de sable, obligándolos a remontarse a la Sierra (Rojo 1987). Transcurrió poco más del año para que se pacificara toda la zona.

El padre Félix Caballero, auxiliado por Jatñil, fundó en junio de 1834 la misión de Guadalupe y, dos meses después, tras el ataque koal a Santa Catalina, se trajo a Guadalupe todo el ganado que tenía en los ranchos 
aledaños a las misiones de Santa Catalina, Santo Tomás y del valle de San Rafael. Aún así, los indígenas de J'cum (Jacumé) aliados con nativos cristianos de Tijuana y San Diego, atacaron varios ranchos, causando destrucción y muertes (Rojo, 1987). De ello da cuenta Jatũil:

Pocos días después salí en campaña con Macedonio González contra los indios de Santa Catalina, los kiliwas y los cucapá, entonces eran muchos; a mí me obedecian mil hombres de guerra; me mataron parte de mis mejores guerreros, nosotros también les matamos muchísimos (Rojo 1987).

Debido a la inestabilidad que las ambiciones políticas crearon en California en su lucha por el poder, algunos gobernantes como Alvarado, con el propósito de amedrentar a los habitantes del sur, prometieron a los indigenas reintegrarles sus tierras. Quizá no se establecieron alianzas formales, pero los jefes de J'cum, (Jacumé), Pedro Pablo, Martín y Cartucho, estaban decididos a recuperar sus tierras, tal como se lo hicieron saber a Antonio Coronel, en el rancho de Otay, durante el mes de julio de 1836. Fue en ese año cuando los indígenas de $J^{\prime} c u m$, en alianza con los kamiai del desierto, iniciaron sus ataques, resultando con más daños el rancho Tecate de Juan Bandini que fue completamente devastado.

En el mes de febrero de 1837, los mismos jefes al frente de 200 guerreros atacaron el rancho de los Argúello, debido a que le tenian un profundo odio a Francisco Argüello como consecuencia del maltrato que siempre les daba y, al no encontrarlo, prendieron fuego a las cosechas, dejando todo en ruinas. El Sargento González salió a perseguirlos y los alcanzo en Tecate, en donde ocurrí una matanza horrible. Los nativos lograron huir hacia J'cum, en donde González de nuevo les causó muchas bajas. Sin embargo, las tribus del Colorado al mando de Charague llegaron en auxilio de los alzados, lo que dio nuevos brios a Cartucho y a Pedro Pablo. Los soldados, 25 en total, se vieron sorprendidos dentro de una cañada, donde hubieran perecido de no arribar Jatñil con sus fuerzas, quien logro rescatarlos. Sin embargo, las mulas y el parque fueron capturados por los insurrectos. Los soldados regresaron a pie a la misión de Guadalupe (Rojo 1987).

Los rancheros de la Alta y Baja California cuipaban al gobiemo de los alzamientos indígenas, señalando que a partir de la secularización de las misiones, los nativos, ya sin el control de los padres, querian a toda costa depredar la zona y recuperar sus tierras. Muchos ranchos fueron abandonados ante el temor de nuevos ataques. Además, las fuerzas presidiales se encontraban propiamente sin cabalgaduras. A esto habrá que agregar que la revuelta de la gente de razón en California, en su lucha por el poder 
local, no contribuía a la pacificación de la zona. Jatñil se vio en la necesidad de replegar a sus gentes hacia la costa; su testimonio es el siguiente:

...Después de que salvé a la escolta que se metió con Macedonio González, en la Sierra de Jacumé, cuando se alzaron Pedro Pablo, Martín y Cartucho, me retiré de la sierra a la costa, porque eran muchísimos los enemigos que allí podían atacarme y vine a hacerme fuerte a un aguaje que hay en la mesa del Descanso, muy a propósito para defendernos... (Rojo 1987).

Tras de un año de lucha, Pedro Pablo y Cartucho, fueron pasados por las armas en la misión de Guadalupe, a cargo del Sargento Narciso Franco; unos cuantos días después arribaron indígenas provenientes del Colorado con intenciones de atacarla, pero fueron sorprendidos por los soldados. De acuerdo al testimonio de don Juan Machado, “...Fue tal la masacre de indios, que resultaba horrible ver tantos cadáveres; así paso el tiempo hasta que sólo veíamos sus huesos..." (Rojo 1987).

Los catecúmenos comenzaron a abandonar las misiones debido a la escasez de alimentos. El Padre Caballero inició la práctica de la leva y los azotes, cuestión que le resultaría contraproducente. Recogemos las impresiones de Clemente Rojo al respecto:

Los indios de las reducciones misionales de la frontera, vivían sin libertad, privados de todos los goces de la vida y obligados a trabajar por la fuerza sin recompensa alguna [...] el que no concluía su tarea que le había dado en la mañana el caporal o mayordomo sufría un castigo desde doce a veinticinco azotes, amarrado a un palo, que con ese objeto había en cada misión [...] después de los castigos, que rara vez faltaban, iban a la iglesia a rezar oraciones de la noche y el rosario de costumbre (Rojas, 1987).

\section{AHORA TE LLAMAS JESÚS}

Jatñil y dos parientes suyos llegaron a la costa de Rosarito en busca de almejas, cuando fueron sorprendidos por hombres a caballo. Jatñil fue apresado y llevado a la misión de San Miguel. He aquí su testimonio:

\footnotetext{
...Al momento que me alcanzaron, me lazaron y arrastraron un largo trecho, estropeandome mucho con las ramas, jalándome lazado como estaba a carrera de sus caballos; después de esto, me amarraron los brazos para atrás y me llevaron por delante a la misión de San Miguel, haciéndome andar casi a la carrera para igualar el trote de sus caballos y cuando paraba un poco para tomar aliento, me azotaban con las reatas (Rojas, 1987).
} 
Jatñil fue encerrado en un cuartucho durante siete días. El padre lo hacía llevar a su aposento con el fin de convencerlo de que aceptara el cristia. nismo. El jefe kamiai relata de la siguiente manera su experiencia:

Un día me echaron agua en la cabeza y me dieron a comer sal, y con esto me dijo el intérprete que ya era cristiano y que me llamaba Jesús. Al día siguiente de mi bautizo, me sacaron a trabajar con los demás indios y me pusieron a limpiar una milpa de maíz; como no sabía manejar el azadón que me dieron [...] me corté el pie y no quise seguir trabajando con él, sino que me puse a arrancar las yerbas con la mano y de este modo no acabé la tarea que me dieron. En la tarde me azotaron porque no acabé con mi tequio, al día siguiente me sucedió lo mismo; todos los días me azotaba injustamente porque no cumplía lo que no sabía hacer (Rojas, 1987).

Días después Jatñil huyó, tomando rumbo a Il kichup (La Zorra) habitada por algunos Mishkwish; sin embargo, poco antes de llegar, fue capturado por los soldados, quienes lo devolvieron a la misión a golpes de reatas. El padre ordenó que lo azotaran, Jatñil perdió el conocimiento y pasó varios días en el cuartucho sin poder moverse. No sabemos cuándo decidió escapar, pero pocos meses después se encontraba en la montaña fraguando un plan para atacar la misión de Guadalupe y deshacerse de una vez por todas del misionero. He aquí su justificación:

... El P. Félix pensó seguramente, que yo no podría volver a la sierra, de miedo, y que me hallaba muy débil para hacer de mí y de mi gente lo que él quisiera; entonces, sin acordarse de mis servicios y de todos nuestros trabajos [...] comenzó a bautizar por la fuerza a la gente de mi tribu que iba a visitarlo, como acostumbrábamos hacerlo. Esto me dio mucho coraje y por eso fui a buscarlo a Guadalupe con la intención de matarlo (Rojas, 1987).

\section{FIN DE LAS MISIONES. JIKU WAMAT AWAT}

En nuestro primer trabajo sobre Jatñil, ubicamos su ataque a la misión de Guadalupe en febrero de 1840, pero nuevas investigaciones, como el testimonio de Juan Bautista Esparza, soldado presidial, nos llevó ha pensar que se efectuó en los primeros días de octubre de 1839. Otro dato que sirve para corroborarlo es la carta fechada en abril de 1840, que el Sargento Gastelum envió a Loreto para el Padre Caballero, notificándole que ya habían terminado el conteo de su ganado, iniciado naturalmente varios meses antes, pues se trataban de 5,269 cabezas (Zárate, 1991b) dispersas por los valles de Guadalupe, San Marcos y San Rafael. Aclarado esto, 
vayamos a los hechos. Jatũil llegó al Valle de Guadalupe acompañado de un buen número de gente armada. A su paso se topó con el teniente Garraleta quien se dirigia a un pequeño llano para hacer sus prácticas; después de saludarse de mano, Jatñil siguió con rumbo a la misión. Sus hombres de inmediato le dieron muerte al Cabo Orantes y a los catecúmenos Francisco y José Antonio que lo acompañaban. Caballo Negro entró a la iglesia preguntando por el Padre Caballero, y éste, al percatarse de lo que sucedfa, solicito el auxilio de la indígena Marfa Gracia, a fin de que lo salvara. Este es el testimonio de María Gracia:

...Estaba sentada sobre el Padre Caballero, habiéndolo ocultado bien entre mi túnica cuando entró Jatríil y me dijo así ....busco al padre porque está bautizando a fuerza a la gente de mi tribu para esclavizarla en la misión, así como estás tú sin gozar de tu libertad y viviendo como animales: dicho esto, el jefe kamiai se retiró y se regresó a la sierra (Rojo, 1987).

Otro testimonio de sumo interés es el de don Juan Machado, quien al respecto nos dice:
...Mucho extraf́é que nadie me hubiera mandado avisar tal cosa y mucbo más todavía que el teniente Garraleta no hubiera salido en persecución de Jatñil, teniendo gente lista y caballos para alcanzarios [...] siempre be creido que Jatnil y Garraleta estaban de acuendo en el hecho (Rojo, 1987).

En el mismo octubre, de acuerdo con testimonios indígenas, los kamiai, koal, cucapá paipai y kolew atacaron la misión de Santa Catalina, mataron a 16 neofitos y quemaron todo el edificio; sin embargo, hace un par de años se localizaron unos documentos que dan una version diferente a los hechos. En ellos se consigna que el ataque se debió a que los indigenas de Santa Catalina dieron muerte a un koal de la rancherfa de La Huerta, por haberlos acusado falsamente del robo de unos ganados; en represalia, los huerteños acabaron con la misión (Zarate, 1991b). Como quiera que fuere, la insurrección era general y el Padre Caballero optó por retirarse de La Frontera encontrando refugio en la misión de San Ignacio, en donde fallecio el 30 de agosto (Zarate, 1991b) envenenado con chocolate servido por un catecúmeno. Asf llego a su fin la época misional en el norte de Baja California, pero no la violencia, pues se desataron nuevamente las guerras intertribales. Jatñil asumió el cargo de kulpay cuatay, es decir, jefe de guerra, y su poderio creció al grado que el resto de los indígenas de $\mathrm{La}$ Frontera desistieron por completo de las acciones bélicas, salvo el caso del jefe Nicuarr, que ocasionalmente se resistía al dominio ejercido por Jatũil; 
sin embargo, nunca fue una amenaza para el jefe kamiai. En las siguientes décadas Jatñil continuó auxiliando al Ejército Mexicano en la persecución de alzados y transgresores de la ley (San Diego Unión, 3 de marzo de 1870).

\section{JATÑIL MISHKWISH}

Para finalizar, incluiremos aquí dos reflexiones, primeramente de Manuel Clemente Rojo (1987):

Los indígenas que vivían en las misiones de la frontera no tenían ninguna libertad, privados de todos los placeres de la vida y obligados por la fuerza a trabajar sin ninguna recompensa. Una hora antes del amanecer eran levantados, fuera verano o invierno, y los llevaban a la iglesia a cantar estrofas y a decir algunas devotas plegarias; palabras que habían aprendido a fuerza de repetirlas pero sin poder comprender lo que decían.

En la última reflexión cedemos el espacio a Jatñil Mishkwish: "Todos los días era azotado porque no hacía lo que no sabía hacer".

\section{BIBLIOGRAFÍA}

ARRILlAGA, José Joaquín. 1804. Carta de Arillaga al Virrey Iturrigaray. Loreto, 24 de octubre de 1804. California Archives, vol. 25. Bancroft Library, Berkeley, California.

BEAN, Lowell y Mason, William. 1962. The Romero Expeditions. 18231826. Palm Springs, Desert Museum, Palm Springs, California.

CORTÉS, Edna Alicia. 1988. "Estudio etnobotánico comparativo de los grupos Indígenas kamiai y paipai del norte de Baja California". Tésis Profesional para obtener el Título de Biologo. Escuela Superior de Ciencias, UABC, Ensenada, B.C.

DU BOIS, Constance. 1905. "Religious Ceremonies, Myths of the Mission Indians". American Anthropological Association, San Francisco, California.

JACK D. 1975. The Yumans of the Quechan Nation and their Neighbors. Norman, University of Oklahoma Press, Oklahoma.

DRUCKER, Philip. 1941. "Culture Elements Distributions XVII: YumanPIMAN”. University of California Anthropological Records, Vol. 6, núm. 3. 
FAGES, Pedro. 1787. "Carta de Pedro Fages a Zúñiga, Monterrey, 5 de marzo de 1787”. California Archives, vol. 23. Bancroft Library, Berkeley, California.

GÓMEZ Canedo, Lino. 1969. De México a la Alta California. Colección México Heroico. Ed. Jus, México, D.F.

HEINTZELMAN, Samuel P. 1857. Report to Major E. D. Townsed, Assistant Adjutant General, U.S.A., Pacific Division, San Francisco, California, datelined Fort Yuma, California, July 15, 1853, House Executive Documents, vol. 9, núm. 76, 34th Congress, 3rd. session. Washington: Comelius Wendell, Printer.

KROEBER, A.L. 1976. Handbook of the Indians of California. Dover Publications, Inc. Nueva York.

MEIGS, Peveril III.1971. "Creation Myth and other Recollections of the Nijhi Mishkwish" Pacific Coast Archaeological, Society, Edición de Baja California. Vol. 7, núm. 1, Orange, California.

ROJO, Manuel Clemente. 1987. "Apuntes históricos de la Baja California". Introducción y notas de David Zarate Loperena. Fuentes documentales para la História de Baja California, año 4, núm. 5, Diciembre. Centro de Investigaciones Históricas, UNAM-UABC, Tijuana, B.C.

SALES, Luis. 1960. Noticias de la Provincia de la California. Colección Chimalistac. José Porrúa Turanzas, Ed. Madrid.

SHIPECK, Florence C. 1970. The Autobiography of Delfina Cuero, a Diegueño Indian. Malki Museum Press, Morongo Indian Reservation, Cal.

- 1982. "Kumeyaay Socio-Political Structure". Journal of California and Great Basin Anthropology. Vol. 4, núm. 2.

VAN Camp Camp, Gena. 1979. Kumeyaay pottery, Ballena Press, California.

WATERMAN, T.T. 1910. Religious practices of the Diegueño indians. University of California Press. Berkeley, California.

ZÁRATE Loperena, David. 1986. "La educación de los kamiai a través de algunas ceremonias". Quinto Simposium de Historia Regional. ACLE, Ensenada, B.C.

— 1987a. "El Hechizo del Oeste". Memoria del Cuarto Simposium de Historia Regional Antonio Melendrez". Asociación Cultural de Liberales de Ensenada y Gobierno del Estado de Baja California, Mexicali, B.C.

- $\quad$ 1987b. "La guerra kamiai en las postrimerías del siglo XVIII y la Fundación de San Miguel Arcángel”. Estudios Fronterizos. Revista 
del Instituto de Investigaciones Sociales. Año V, Vol. V. núm. 14. Sept-dic. UABC. Mexicali, B.C.

- 1991a. "Testimonios de Santo Tomás: La muerte del P. Eudaldo Surroca en 1803". Memoria del Décimo Simposium de Historia Regional. Asociación Cultural de Liberales de Ensenada y Depto. de Extensión Universitaria UABC, Ensenada, B.C.

- 1991b. "Los ranchos del valle de San Rafael". Memoria 1991, Seminario de Historia de Baja California, Ensenada, B.C.

\section{Periódicos consultados}

San Diego Unión, 3 de marzo de 1870, San Diego, California. 